Information Design Journal 26(1) p. 73-88

(c) 2021 John Benjamins Publishing Company doi.org/10.1075/idj.19033.bei

Publication date: April 28, 2021

Sofie Beier, Chiron A. T. Oderkerk, Birte Bay \& Michael Larsen

๖ Available under the CC BY-NC 4.0 license

\title{
Increased letter spacing and greater letter width improve reading acuity in low vision readers
}

Keywords: low vision, legibility, font, letter spacing, letter width

Low vision readers depend on magnification, but magnification reduces the amount of text that can be overviewed and hampers text navigation. In this study, we evaluate the effects that font variations letter spacing, letter width, and letter boldness have on low vision reading. We tested 20 low-vision patients with age-related macular degeneration (AMD) and used the Radner Reading Chart, which measures reading acuity $(\log R A D)$, maximum reading speed, and critical print size. The results demonstrated a small, but measurable effect of letter spacing and letter width on reading acuity near critical font sizes.

\section{Introduction}

For people with subnormal vision, reading impairment is a significant educational and socio-economic burden and affects quality of life (Brown et al., 2014). Text magnification is a standard method to support reading for people with limited vision, but magnification comes at the cost of a reduced overview of the body of the text. Additionally, the task of maneuvering a printed page or a digital screen presentation using an optical or an electronic magnifier requires panning, zooming, memorizing, and planning, making the comprehension of the text itself an even bigger challenge (Szpiro et al., 2016; Tunold et al., 2019).

In most industrialized countries, age-related macular degeneration (AMD) is the most common cause of visual loss in people above the age of 60 years (Wong et al., 2014). Its functional hallmark is the selective loss of central vision. Low-vision readers with AMD can benefit considerably from magnification (Legge et al., 1985). The degree of visual acuity reduction is important because magnified words may outgrow the area of useful visual field and force the reader to read segments of words rather than whole words (Fletcher et al., 1999; Neelam et al., 2009). Additionally, visual crowding, i.e., the interference of neighboring letters with the identification of a given letter, increases with eccentricity (Wallace et al., 2017). These constraints make it vitally important that fonts are optimized for low vision so that letter sizes can be kept at the minimum needed for reading (S. T. Chung et al., 1998; Virsu \& Rovamo, 1979).

Several organizations for the blind and visually impaired promote the use of sans serif fonts with even stroke modulation, meaning that there is little contrast between thin and thick parts of the letters, such as Arial and Helvetica (Action for blind people, 2004; Galvin, 2014; Kitchel, 2013). There is, however, no clearly 
traceable evidence base for these recommendations

(Arditi, 2017; Baines, 2004).

Attempts have been made to identify fonts that are optimal for reading with low vision secondary to macular degeneration, using the reading test MNREAD to assess individual performance parameters (Mansfield et al., 1996; Tarita-Nistor et al., 2013; Xiong et al., 2018). Low vision subjects, with or without a central scotoma, have been found to perform better with Courier Bold than with Times Roman in terms of reading acuity, maximum reading speed, and critical print size (CPS; Mansfield et al., 1996). This is in contrast to people with normal vision, where maximum reading speed was better with Times Roman, although reading acuity was better with Courier Bold (Mansfield et al., 1996). The same methodology was employed in another experiment that tested Courier Regular and Times New Roman, as well as two additional fonts, namely Arial and Andala Mono. It was found that Courier was associated with better reading acuity in AMD patients (Tarita-Nistor et al., 2013). A third experiment measured the effects of fonts designed for MD patients (Eido and Maxular) and fonts of more regular use (Helvetica, Times Roman, and Courier Regular), and also showed that of all test fonts, Courier Regular resulted in the best reading acuity (Xiong et al., 2018).

Tarita-Nistor et al. (2013) and Xiong et al. (2018) examined the area occupied by their test fonts by measuring the spatial area covered by each line of text in the sentences and the average center-to-center distance between neighboring letters, respectively. In both cases, it was found that increased horizontal spacing was beneficial. Tarita-Nistor et al. (2013) found that it had a positive effect on reading acuity, and Xiong et al. (2018) found that it had a positive effect on reading acuity and CPS, although it had a negative effect on maximum reading speed.

The horizontal spatial area covered by the font can be further divided into two typographical variables, namely
(1) letter spacing and (2) letter width. The main objective of the present study was to identify the specific font design parameters responsible for the apparent superiority of Courier over Times in prior studies of reading performance in people with macular degeneration.

\section{Methods}

\subsection{Participants}

Based on the previous findings by Tarita-Nistor et al. (2013), this intraindividual comparison of font readability was powered to have an $80 \%$ chance of detecting a significant difference in reading acuity score between the control font and each modified font. We tested 20 participants with AMD (mean age $=84.35$ years, $S D=6.24$ years, 12 women), all recruited from the Medical Retina outpatient clinic of the Department of Ophthalmology at the Rigshospitalet. All participants had Danish as their first language and had no relevant competing handicap, such as aphasia or dementia. Inclusion criteria included having a Snellen decimal visual acuity between 0.1 and 0.5 in the participant's better-seeing eye. Participants used their usual spectacle correction for reading but no low vision aids.

The study population was limited to the Snellen BCVA range $0.1-0.5$ (decimal notation) in the better-seeing eye because (1) patients with BCVA better than 0.5 have little need for visual rehabilitation and (2) the Rigshospitalet medical retina clinic has relatively few active patients with BCVA worse than 0.1 in the better-seeing eye. Rare patient types often have complex characteristics and may lead to overrepresentation of outliers. All eyes were monitored at regular, individualized intervals in the medical retina clinic of Rigshospitalet for neovascular AMD activity, and treated using intravitreal VEGF inhibitor injection as needed to prevent or control recurrence of choroidal neovascularization activity (Rasmussen et al., 2013, 2015). 


\subsection{Test material}

The methodology of this study is illustrated in Figure 1 by highlighting the font parameters letter width, letter spacing, and letter boldness for Courier Bold, Courier Regular, and Times New Roman Regular. We selectively adjusted these three variables in three separate fonts of Time New Roman (Figure 2). The effect on reading outcomes was measured in readers with moderate visual loss due to age-related macular degeneration using the texts, layout, procedure, and other principles of the Radner Reading Chart.

The font Times New Roman Regular ${ }^{1}$ was modified to create two new fonts. The first version was Times New Roman where the letter width was visually adjusted to match that of Courier Bold (TNR Width), other parameters such as font boldness and letter spacing remaining the same (due to the large serifs on the letters ' $i$ ' and 'l' these letters can appear to have additional spacing, yet they do not). The second version was Times New Roman

\section{hamburgefontsiv}

\section{hamburgefontsiv

\section{hamburgefontsiv \\ Times New Roman}

Edge-to-edge spacing

- Letter-shape width

Letter boldness

Figure 1. Highlighted illustration of the font characteristics letter width, letter spacing, and letter boldness

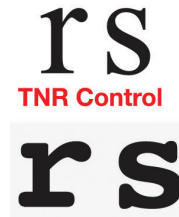

Courier Bold

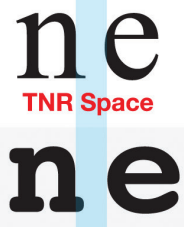

Courier Bold

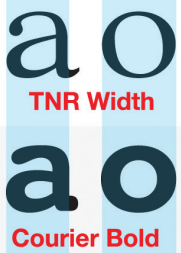

Courier Bold

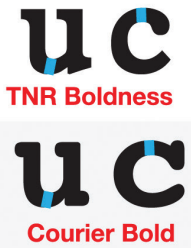

Courier Bold

Figure 2. Test fonts, top row from left: TNR Control (Times New Roman), TNR Space (Times New Roman with added letter spacing of 90 units in Adobe InDesign), TNR Width (Times New Roman redesigned with horizontal letter proportions similar to those of Courier Bold), TNR Boldness (Times New Roman redesigned with boldness similar to Courier Bold). The bottom row is Courier Bold 


\section{Min morfar havde også tømt sit handskerum, hvor vi børn stadig gemte alle æbleskrog \\ TNR Control (Times New Roman)}

\section{Min morfar havde også tømt sit handskerum, hvor vi børn stadig gemte alle æbleskrog \\ TNR Space (Times New Roman +90 spacing unites in Adobe Indesign)}

Den mandag ville Lasse hente sin dværgkanin, som hans ven havde passet hele weekenden TNR Width (Times New Roman with letter width as Courier Bold)

\section{Den mandag ville Lasse hente sin dværgkanin, som hans ven havde passet hele weekenden}

TNR Boldness (Times New Roman with letter boldness as Courier Bold)

\section{the quick brown fox jumps over a lazy dog Courier Bold}

Figure 3. Text and font specimens. The top four fonts were tested in the study

where the boldness was visually adjusted to match Courier Bold (TNR Boldness), while letter spacing remained unchanged. Letter width was slightly changed only by the amount of added surface area covered by the extra weight of the letters. In addition to this, we included a third version of Times New Roman Regular with added spacing in the form of 90 Adobe InDesign spacing units, which is $90 / 1000$ of the font size (TNR Space) (Figures 2 and 3). This added space both between letters and between words. The added spacing was visually adjusted to match the overall letter spacing of Courier. We chose not to adopt the uneven spacing that is inherent in a fixed-width font such as Courier because it is generally accepted that uneven spacing makes reading more cumbersome (Beier, 2017; Tracy, 1986; Unger, 2018). Reading performance was compared for each of the three modified fonts with the original Times New Roman Regular (TNR Control).

\subsection{Experimental design}

For this experiment, we used the Danish version of the Radner Reading Chart, which has 28 original sentences (Munch et al., 2016). This chart enables measurement of logarithmic reading acuity (logRAD), which is the reading acuity equivalent of the logMAR unit (Radner, 2017), this is defined as the common logarithm of the minimum angle of resolution in minutes of arc. The Radner Reading Chart employs scaled sentence optotypes, standardized for syntax as well as lexical and grammatical difficulty, to simultaneously measure both reading speed and reading acuity (Radner, 2017). It has been found to be reliable for clinical testing in low vision populations (Burggraaff et al., 2010) and has been clinically tested in several languages, including Danish (Munch et al., 2016), German (Radner et al., 2002), Spanish (Alió et al., 2008), and Dutch (Maaijwee et al., 2008). It has further been empirically 
tested in English (Radner \& Diendorfer, 2014), Portuguese (Rosa et al., 2016), and Italian (Calossi et al., 2014).

Each participant was presented with four different test sheets in Danish (16 test sheets in total across participants), one for each of the font conditions. For each sheet of 11 sentences in order of decreasing font size from top to bottom, the top four were identical to the bottom four on one of the other sheets; on two sheets the top four sentences were identical to the bottom four of a preceding sheet; and on two sheets the top four sentences were identical to the bottom four of a subsequent sheet. The test material was printed as Indigo digital print (1625 dpi) on 200 gr. Scandia White paper. The font size decreased in equal proportions, from the largest size of $57.8 \mathrm{pt}$. (1.2 $\log \mathrm{RAD}$ at $40 \mathrm{~cm}$ reading distance) to the smallest font size of $5.8 \mathrm{pt}$. (0.2 $\log \mathrm{RAD}$ at $40 \mathrm{~cm}$ reading distance). The sheets were interchangeable so that the sentences and font combination changed between participants. The presentation of fonts followed the rotating sequence TNR Control, TNR Width, TNR Space, TNR Boldness, the starting font varying from participant to participant so that a given font was read first, second, third, and last by an equal number of participants.

The research followed the tenets of the Declaration of Helsinki and the Danish Code of Conduct for Research Integrity. The study does not fall under the legal requirements for medical ethics review in Denmark and adheres to the data protection regulations of the European Union. Written consent was obtained after the participants had been informed about the nature of the experiment.

\subsection{Procedure}

Testing took place in a well-lit room, in which a bright reading lamp illuminated the reading chart. An audio recorder was used to record the sessions, and the audio recordings were used to determine the participant's reading speed and reading errors.
The reading distance was determined for each participant individually at the beginning of the testing session. Specifically, a reading distance was selected so that the participant was unable to fluently read more than $80 \%$ of the third-smallest sentence on a pre-test chart of alternative sentences set in Helvetica Neue. The average reading distance was $32.38 \mathrm{~cm}(S D=7.42 \mathrm{~cm})$. The test material was placed in front of the participants on a simple lecture stand at an angle of 130 degrees with the horizontal. Participants read binocularly and were instructed to read every sentence aloud as quickly and as accurately as they were able to, without correcting any errors. The experimenter revealed the sentences one at a time and simultaneously gave participants an auditory one-word instruction to begin reading. Starting with the largest print size, participants read all sentences aloud until they could not accomplish correct reading of $80 \%$ or more of the words in a sentence.

\subsection{Data analysis}

The three variables determined were reading acuity in logRAD units, maximum reading speed in words per minute (WPM), and critical print size (CPS) in $\log \mathrm{RAD}$ units. The reading acuity $\log \mathrm{RAD}$ score for each font was defined as the $\log \mathrm{RAD}$ value of the smallest font that enabled correct reading of $80 \%$ or more of the words in a sentence, corrected for the number of errors made while reading the smallest font size ( $\log$ RAD score $=\operatorname{logRAD}+0.005 \mathrm{X}$ syllables of incorrectly read words; Maaijwee et al., 2008).

The reading time for each sentence was measured from the onset of the experimenter's signal to begin reading, using an audio recording of the testing session and a stopwatch. Reading speed was determined as the number of words read correctly over the reading time. As each sentence comprised 14 words, the reading speed (in WPM) was equal to 14 words, minus the number of 
incorrectly read words, multiplied by $60 \mathrm{~s}$, divided by the reading time.

The maximum reading speed was determined as the geometric mean of a plateau of reading speed values, of which all reading speeds were within two standard deviations of the mean reading speed of the plateau (Mansfield et al., 1996). The critical print size was defined as the logRAD letter size of the sentence set with the smallest font, the reading time of which was within the maximum reading speed plateau (Figure 4). Both reading acuity and critical print size were corrected for each participants' reading distance.

Reading acuity, maximum reading speed, and critical print size (CPS) were analyzed using ANOVA procedures for repeated measurements of the four study fonts (TNR Control, TNR Boldness, TNR Space, and TNR Width). Significant effects were further analyzed using planned t-tests, corrected for multiple comparisons using the
Figure 4. Radner test results of the control font from patient no. 15, whose best eye had best-corrected distance visual acuity logMAR 0.3 (Snellen 0.5) recorded at presentation, before visual rehabilitation, using the patient's habitual near-vision addition. Sentences were read within the nominal plateau time-frame of 8.63 seconds, which defines the patient's maximum reading speed of 120.68 words per minute, down to logRAD o.6, which defines the patient's critical print size. The reading time increased from thereon down to the smallest print size that could be read, logRAD 0.4, which represents the patient's reading acuity. The maximum reading speed is the geometric mean reading time within the plateau from the largest print down to and including the critical print size. The CPS is the smallest font size at which the participant's reading speed is within two standard deviations of the maximum reading speed. Reading acuity is the smallest font size at which the participant can read at any reading speed, corrected for errors

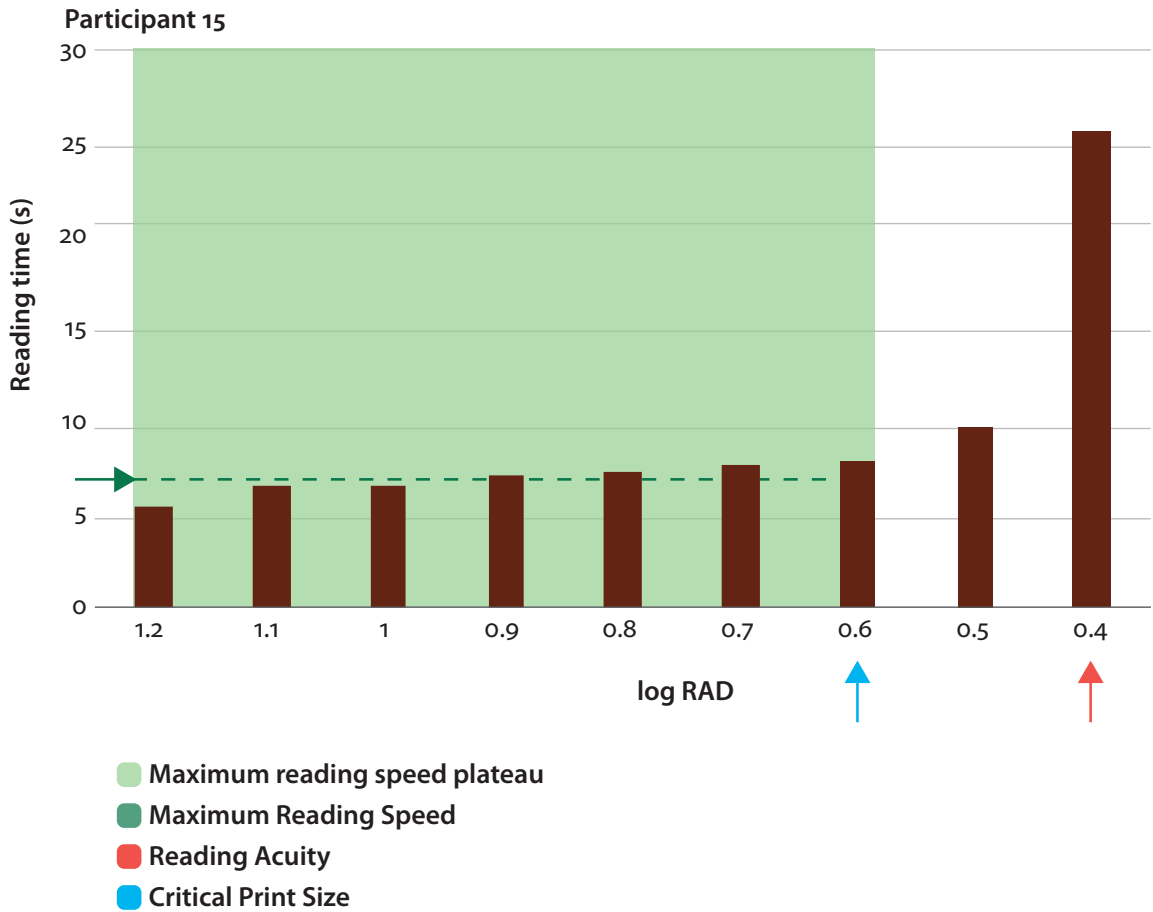


Bonferroni method, comparing performance with TNR Control to performance with TNR Boldness, TNR Space, and TNR Width and using $p<.05$ as the level of statistical significance. We were unable to determine the maximum reading speed and critical print size for one or more fonts in three participants, as their performances were too poor to allow the determination of these variables.

\section{Results}

The study population of 20 AMD patients with a mean age of 84.4 (range 71-95) years had a mean $\pm S D$ $\operatorname{logMAR}$ visual acuity of $0.42 \pm 0.12$ in the better-seeing eye (Table 1 ).

Table 1. Characteristics of study population of the 20 patients, 10 had wet AMD in both eyes, whereas 10 had wet AMD in one eye and dry AMD in the fellow eye

\begin{tabular}{|c|c|c|c|c|c|c|c|}
\hline ID & Age & Gender & $\begin{array}{c}\text { Diagnosis } \\
\text { OD/OS }\end{array}$ & $\begin{array}{l}\text { logMAR distance visual } \\
\text { acuity in better-seeing eye } \\
\text { (Snellen decimal acuity) }\end{array}$ & $\begin{array}{c}\text { Mean reading } \\
\text { acuity [logRAD] }\end{array}$ & $\begin{array}{l}\text { Mean reading } \\
\text { speed [WPM] }\end{array}$ & $\begin{array}{l}\text { Mean critical } \\
\text { print size } \\
\text { [logRAD] }\end{array}$ \\
\hline 1 & 86 & M & Wet/dry AMD & OS $0.5(0.3)$ & 0.64 & 146.51 & 1.02 \\
\hline 2 & 82 & M & Dry/wet AMD & OD $0.3(0.5)$ & 0.29 & 140.59 & 0.95 \\
\hline 3 & 80 & M & Wet/dry AMD & $0.4(0.4)$ & 0.81 & 128.94 & 1.07 \\
\hline 4 & 87 & $\mathrm{~F}$ & Wet/dry AMD & $0.7(0.2)$ & 0.88 & 47.39 & 1.05 \\
\hline 5 & 95 & $\mathrm{~F}$ & Wet/dry AMD & OS $0.3(0.5)$ & 0.55 & 117.95 & 1.05 \\
\hline $6^{*}$ & 84 & $F$ & Wet/dry AMD & OD $0.7(0.2)$ & 0.87 & 44.22 & 1.12 \\
\hline 7 & 91 & $F$ & Wet/wet AMD & OD $0.3(0.5)$ & 0.40 & 108.96 & 0.85 \\
\hline 8 & 93 & M & Wet/wet AMD & OS $0.5(0.3)$ & 1.19 & 17.75 & 1.30 \\
\hline $9^{*}$ & 80 & $\mathrm{~F}$ & Wet/wet AMD & $0.5(0.3)$ & 1.07 & 22.68 & 1.10 \\
\hline 10 & 80 & $\mathrm{~F}$ & Wet/dry AMD & OD 0.4 (0.4) & 0.55 & 137.32 & 1.02 \\
\hline 11 & 83 & M & Wet/dry AMD & OD $0.3(0.5)$ & 0.22 & 160.81 & 0.85 \\
\hline 12 & 79 & $\mathrm{~F}$ & Wet/wet AMD & OS $0.4(0.4)$ & 0.83 & 19.09 & 1.13 \\
\hline $13^{*}$ & 71 & M & Wet/dry AMD & OS $0.3(0.5)$ & 0.52 & 104.72 & 0.99 \\
\hline 14 & 88 & $\mathrm{~F}$ & Wet/wet AMD & OD $0.4(0.4)$ & 0.99 & 69.93 & 1.12 \\
\hline 15 & 93 & M & Wet/dry AMD & OS $0.3(0.5)$ & 0.47 & 102.49 & 0.88 \\
\hline 16 & 80 & $\mathrm{~F}$ & Wet/wet AMD & OS $0.3(0.5)$ & 0.82 & 110.13 & 1.16 \\
\hline 17 & 91 & M & Wet/wet AMD & OD $0.4(0.4)$ & 0.47 & 114.57 & 1.19 \\
\hline 18 & 78 & $\mathrm{~F}$ & Wet/wet AMD & OD 0.5 (0.3) & 0.33 & 113.22 & 0.64 \\
\hline 19 & 79 & $\mathrm{~F}$ & Wet/wet AMD & OD $0.4(0.4)$ & 0.56 & 109.03 & 0.95 \\
\hline 20 & 87 & $F$ & Wet/wet AMD & OD $0.4(0.4)$ & 0.36 & 127.53 & 0.99 \\
\hline
\end{tabular}

* Maximum reading speed and critical print size could not be defined for one or more fonts. 


\subsection{Reading acuity}

Compared to TNR Control, all modified fonts showed higher reading acuity scores in the study population, which reached statistical significance for the fonts TNR Space and TNR Width, whereas the effects of the modifications made in the font TNR Boldness did not reach significance. In repeated-measures ANOVA we found a significant effect of font on $\log \mathrm{RAD}$ scores, $F(3,57)=2.90, p=.043, \eta p^{2}=0.132$ (Figure 5). Pairwise comparisons can be found in Table 2 . The correlation between TNR Control and modified fonts was high, rs $(18)=.97-.99, p<.001$.

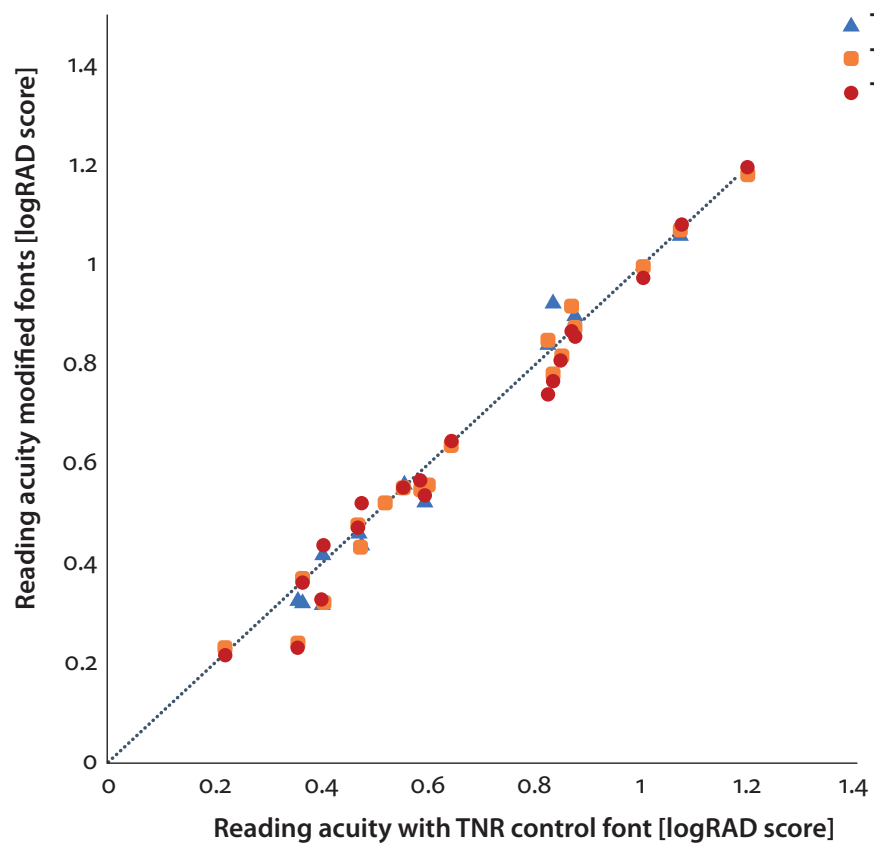

\subsection{Maximum reading speed}

There was no significant overall effect of font on maximum reading speed, $F(3,48)=0.18, p=.912, \eta p^{2}=0.011$ (Figure 6). The correlation between TNR Control and modified fonts was $\mathrm{rs}(17)=.78-.83, p<.004$, and thus lower than for reading acuity.

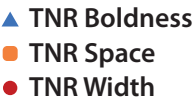

TNR Boldne
TNR Space

TNR Width

Figure 5. Binocular reading acuity score in log RAD units ( $0=$ Snellen 1.0, 1 = Snellen 0.1) for modified boldness, space, and width of the standard Times New Roman font in relation to the standard Times New Roman Control font in 20 patients with age-related macular degeneration. Markers on the dashed identity line represent no change. Markers below the identity line represent better performance of the modified font than the control font, markers above the identity line represent worse performance than the control 
Table 2. Reading acuity, maximum reading speed and critical print size in relation to font type

\begin{tabular}{lcccc}
\hline Font & $\begin{array}{c}\text { Bonferroni-corrected two-tailed paired } \\
\text { samples } \boldsymbol{t} \text {-test between mean reading } \\
\text { acuity for TNR Control and test fonts }\end{array}$ & $\begin{array}{c}\text { Mean reading } \\
\text { acuity [logRAD] (SD) }\end{array}$ & $\begin{array}{c}\text { Mean maximum } \\
\text { reading speed } \\
\text { [WPM] (SD) } \\
(\boldsymbol{n}=\mathbf{1 7})\end{array}$ & $\begin{array}{c}\text { Mean critical print } \\
\text { size [logRAD] (SD) }\end{array}$ \\
\hline TNR Control & - & $0.66(0.27)$ & $104.69(47.71)$ & $\mathbf{( n = 1 7 )}$ \\
TNR Boldness & $t(19)=1.35, p>.580, d=0.30$ & $0.65(0.28)$ & $102.71(42.64)$ & $0.95(0.27)$ \\
TNR Space & $t(19)=2.65, p=.048, d=0.59$ & $0.63(0.29)$ & $103.30(42.42)$ & $1.06(0.28)$ \\
TNR Width & $t(19)=2.63, p=.0497, d=0.59$ & $0.63(0.27)$ & $106.30(43.42)$ & $1.04(0.19)$ \\
\hline
\end{tabular}

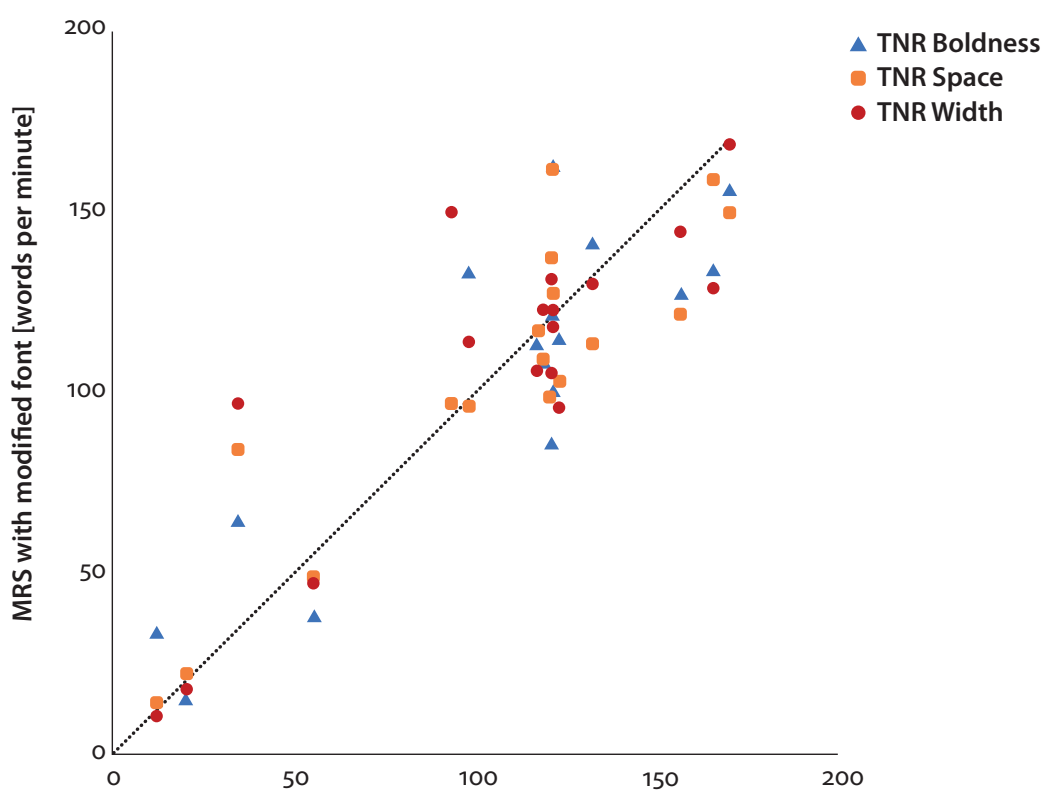

MRS with TNR control font [words per minute]
Figure 6. Binocular maximum reading speed in words per minute for modified boldness, space, and width of the standard Times New Roman font in relation to the standard Times New Roman Control font in 17 patients with age-related macular degeneration. Markers on the dashed identity line represent no change. Markers above the identity line represent better performance of the modified font than the control font, markers below the identity line represent worse performance than the control 


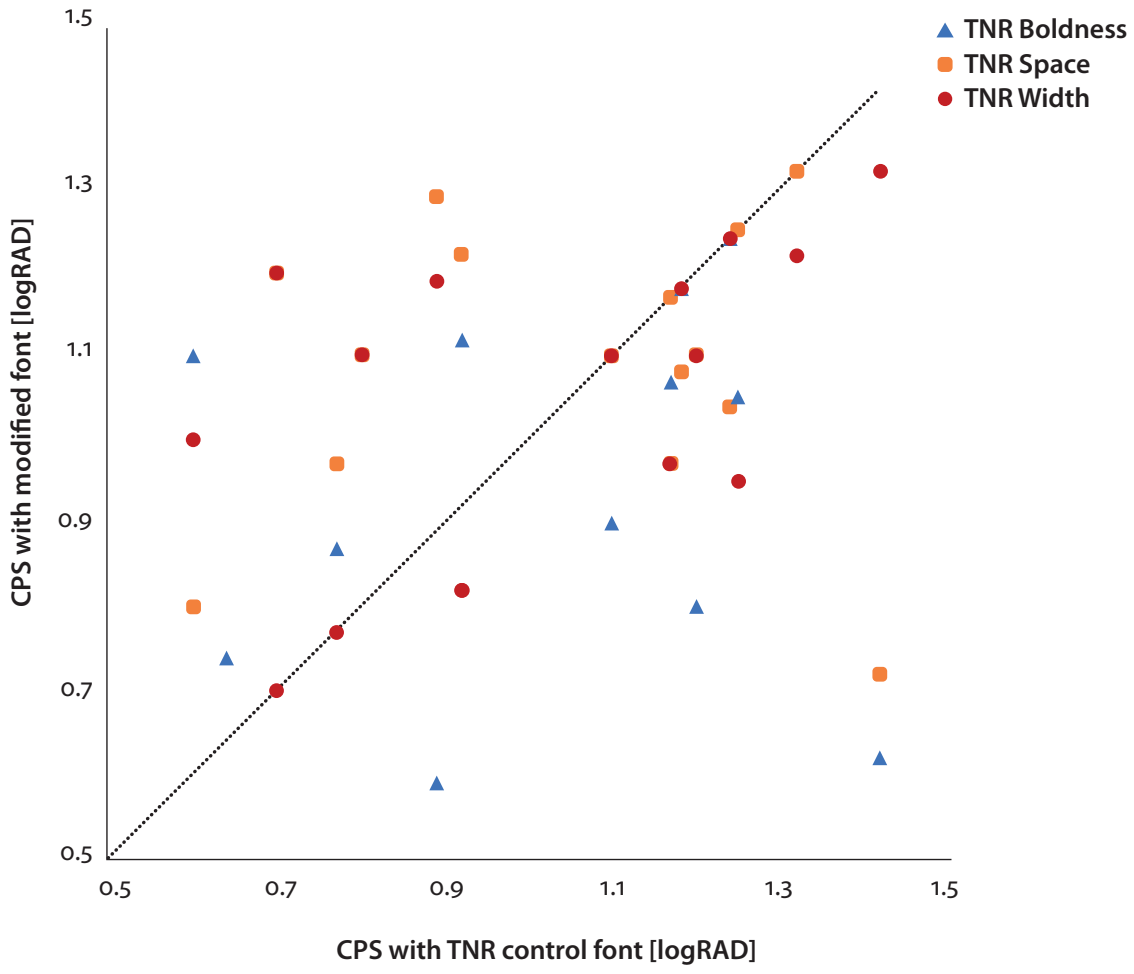

Figure 7. Binocular critical print size in log RAD units $(\mathrm{o}=$ Snellen 1.0, $1=$ Snellen 0.1) for modified boldness, space, and width of the standard Times New Roman font in relation to the standard Times New Roman Control font in 17 patients with age-related macular degeneration. Markers on the dashed identity line represent no change. Markers below the identity line represent better performance of the modified font than the control font, markers above the identity line represent worse performance than the control

\subsection{Critical print size}

There was no significant overall effect of font on mean critical print size, $F(3,48)=0.93, p=.432, \eta p^{2}=0.055$ (Figure 7). The correlation between TNR Control and modified fonts was $\mathrm{rs}(17)=.14^{-} .55, p<.571$, and hence lower than for both reading acuity and maximum reading speed.

\section{Discussion}

This study found that, although relatively small, there is a significant improvement in reading acuity with increased spacing of letters (TNR Space) and wider letters (TNR Width). We also showed that there were no systematic effects of the choice of font on reading speed or critical print size as measured in this study. 


\subsection{Isolating font variables}

It is a common approach among reading researchers to compare the performance of fonts belonging to different font families. Various methodological approaches have been applied to compare the legibility of different fonts in people with normal vision in relation to maximum reading distance (Philip M Garvey et al., 2001; Phillip M Garvey et al., 2016; Smuc et al., 2007; Waller, 2007), reading speed (Bernard et al., 2001; Soleimani \& Mohammadi, 2012; Yager et al., 1998), short-exposure reading (Kingery \& Furuta, 1997; Pušnik et al., 2016), and reaction times in lexical decision tasks (Dobres et al., 2015). However, the test fonts often vary on so many visual parameters, that it is difficult to identify the specific feature that drives a given difference in performance between fonts (Beier, 2016). Isolation of a given variable requires manipulation of this variable only, while the others are kept constant. When researchers are able to alter the test fonts so that only one variable is changed, they may succeed in identifying the effect of specific typographical features such as serifs (Arditi \& Cho, 2005; Beier \& Dyson, 2014; Morris et al., 2002), letter skeleton (Beier et al., 2018; Beier \& Larson, 2010; Larson \& Carter, 2016) and letter boldness (Beier \& Oderkerk, 2019b). The present experiment employs this methodological paradigm to demonstrate that isolated font variables alone can induce significant differences in reading acuity in AMD patients. However, this approach can be challenging as typographic variables tend to interact (Beier, 2016). This became evident while we designed the new test fonts for the present experiment. When we adapted the serif style of Courier to Times New Roman, it resulted in visibly wider letter spacing for some letters, and when we added boldness to Times New Roman Regular, it resulted in wider letter shapes and smaller letter counters. Complete isolation of typographic variables within legibility research is not always possible, but demonstrated here, the approximate isolation of variables can provide new knowledge that is difficult to gain from the font comparison paradigm alone.

\subsection{Letter boldness}

For participants with normal vision, multiple experiments have shown positive effects of letter boldness for text emphasis (Bateman et al., 2008; Dyson \& Beier, 2016), small font sizes (Beier \& Oderkerk, 2019b; Sheedy et al., 2005), and low luminance conditions (Burmistrov et al., 2016). However, our findings failed to show that letter boldness improves low vision reading. This follows the findings of a previous study which showed no difference in low vision reading speed between different font weights of Courier, similar to the font weights of our study (Chung \& Bernard, 2018).

\subsection{Horizontal area}

Xiong et al. (2018) demonstrated that fonts that cover a greater horizontal area slowed down reading speed but improved CPS and reading acuity in AMD patients, and similar results were found in older subjects with normal vision (Beier \& Oderkerk, 2019a). The greater horizontal extent can be based either on greater letter spacing or on wider letter shapes. By isolating the two font variables and comparing these with Times New Roman (TNR Control), the outcome of the present study suggests that the reason why Courier has frequently shown better reading acuity in AMD patients relates to its wider letter shape and greater letter spacing.

These two variables are apparently strong enough, independently, to yield significant, albeit relatively minor, performance improvements. Greater letter spacing and greater letter width both occupy more 
horizontal space. Traditional magnified fonts are scaled proportionally and therefore take up both more vertical and horizontal surface area. Our findings indicate a positive effect of fonts that only take up more horizontal surface area.

Since the early days of printing, type founders knew that fonts need certain visual features to maximize reading acuity. Fonts were created in physical sizes, meaning that the type founder could design each font to the physical size it would be printed in, which allowed for optical scaling between sizes. The tradition was to create smaller font sizes with wider letter shapes and larger letter spacing. In addition to this, there was a tendency for smaller font sizes to have larger $\mathrm{x}$-height (the letter part that has a vertical height identical to the lowercase ' $x$ ') and lower contrast between thin and thick parts of the letters (Ahrens \& Mugikura, 2014; Carter, 1937). Our results validate the font design tradition of producing smaller font sizes of greater letter spacing and wider letter shape for low vision reading.

\subsection{Letter spacing}

It is a well-described phenomenon that greater letter spacing minimizes the effect of visual crowding, i.e., the reduction of letter recognizability which occurs when a letter is flanked by one or more other letters (Bouma, 1970), especially in the peripheral visual field where many patients with macular degeneration are forced to read. As AMD patients often depend on their visual periphery for reading, this could explain the improved performance with wider letter spacing. However, others have demonstrated great variation in AMD participants' performances when investigating the effects of letter spacing and letter size, finding greater letter spacing not to be equally important for all AMD patients (Chung, 2014).
Our results follow previous research on normal vision participants, which demonstrated that increased letter spacing benefits visual acuity (Hess et al., 2000; Liu \& Arditi, 2001). Likewise, it has been shown that for people with normal vision, increased letter spacing accelerates reading of small fonts, but not large fonts sizes, it does not do so for larger font sizes (Arditi et al., 1990). This could explain why we failed to find any effect of increased letter spacing on reading speed, since the majority of the paragraphs read were at sizes above critical print size.

\subsection{Implications of the results}

A methodological limitation of the experiment is that the Radner Reading Chart only has 28 validated sentences. There is a risk that the repeated sentences between larger and smaller font sizes could have influenced the results; however, the limitation was identical across conditions.

It is encouraging that both letter spacing and letter width could be seen to have positive effects on low vision reading when isolated. The effects found in this study were of minor magnitude, but so were the changes that were imposed on the font. This choice was driven by the key premise of guiding the selection and design of new fonts for low vision reading. Our results provide new information for designers that can potentially be implemented in user-driven reading applications, on medicine labeling, street signage, vehicle displays or any other context where reading errors need minimization. Communication for the visually impaired is becoming increasingly multimodal, offering visual, auditory, and tactile input, and providing adaptive user-controlled adjustments, which can potentially allow for infinite presentation options. To avoid ineffectiveness, one needs to 
know how to prioritize. Our study is a contribution to this development.

Previous research has found a wide variation in reading rates between different groups of low-vision readers, with $64 \%$ of the variation being attributable to the distinction of intact central fields versus central field loss and excessively cloudy versus clear ocular media (Legge et al., 1985). Thus, an interesting follow-up experiment should include a larger pool of visual impaired participants with diagnoses other than AMD.

\section{Conclusion}

The reading acuity of AMD patients with low visual acuity improved with wider letter shapes and wider letter spacing. Within low vision rehabilitation, the findings support the need to change the paradigm away from the recommendation of specific fonts to the recommendation of font characteristics. This may promote informed choices between presentation options and faster development of new presentation modalities.

\section{Note}

1. Permission to alter Times New Roman for the project was granted by Monotype Imaging Inc.

\section{Submission date: 14 September, 2020 \\ Accepted date: 9 February, 2021}

\section{Funding information}

This study was supported by grants from the Danish Council for Independent Research [grant number DFF - 7013-00039] and from the Danish Eye Research Foundation (Øjenfonden).

\section{References}

Action for blind people. (2004). Making it clear: Guidelines to producing printed material for people who are blind or partially sighted. Retrieved from https://s27807.pcdn.co/ wp-content/uploads/making_it_clear_guidelines-afsl.pdf

Ahrens, T., \& Mugikura, S. (2014). Size-specific adjustments to type designs: An investigation of the principles guiding the design of optical sizes. Just Another Foundry.

Alió, J. L., Radner, W., Plaza-Puche, A. B., Ortiz, D., Neipp, C. M., Quiles, J. M., \& Rodríguez-Marín, J. (2008). Design of short Spanish sentences for measuring reading performance: Radner-Vissum test: Journal of Cataract \& Refractive Surgery, 34(4), 638-642. https://doi.org/10.1016/j.jcrs.2007.11.046

Arditi, A., Knoblauch, K., \& Grunwald, I. (1990). Reading with fixed and variable character pitch', Journal of the Optical Society of America, 7(10), 2011-2015. https://doi.org/10.1364/JOSAA.7.002011

Arditi, Aries. (2017). Rethinking ADA signage standards for low-vision accessibility. Journal of Vision, 17(5), 8-8. https://doi.org/10.1167/17.5.8

Arditi, Aries, \& Cho, J. (2005). Serifs and font legibility. Vision Research, 45(23), 2926-2933. https://doi.org/10.1016/j.visres.2005.06.013

Baines, P. (2004). The end of typography: Slow death by default. Eye Magazine, Spring.

Bateman, S., Gutwin, C., \& Nacenta, M. (2008). Seeing things in the clouds: The effect of visual features on tag cloud selections. In Proceedings of the nineteenth ACM conference on Hypertext and hypermedia (pp. 193-202). https://doi.org/10.1145/1379092.1379130

Beier, S. (2016). Letterform Research: An academic orphan. Visible Language, 50(2), 64

Beier, S. (2017). Type Tricks: Your personal guide to type design. BIS Publishers.

Beier, S., Bernard, J.-B., \& Castet, E. (2018). Numeral legibility and visual complexity. In DRS Design Research Society, 2018: Limerick. https://doi.org/10.21606/drs.2018.246

Beier, S., \& Dyson, M. C. (2014). The influence of serifs on ' $h$ ' and ' $i$ ': Useful knowledge from design-led scientific research. Visible Language, 47(3), 74-95. 
Beier, S., \& Larson, K. (2010). Design Improvements for Frequently Misrecognized Letters. Information Design Journal, 18(2), 118-137. https://doi.org/10.1075/idj.18.2.03bei

Beier, S., \& Oderkerk, C. A. T. (2019a). The effect of age and font on reading ability. Visible Language, 53(3), 51-69.

Beier, S., \& Oderkerk, C. A. T. (2019b). Smaller visual angles show greater benefit of letter boldness than larger visual angles. Acta Psychologica, 199, 102904. https://doi.org/10.1016/j. actpsy.2019.102904

Bernard, M., Liao, C. H., \& Mills, M. (2001). The effects of font type and size on the legibility and reading time of online text by older adults. In CHI'01 extended abstracts on Human factors in computing systems (pp. 175-176).

https://doi.org/10.1145/634067.634173

Bouma, H. (1970). Interaction effects in parafoveal letter recognition. Nature, 226, 177-178. https://doi.org/10.1038/226177ao

Brown, J. C., Goldstein, J. E., Chan, T. L., Massof, R., Ramulu, P., \& Low Vision Research Network Study Group. (2014). Characterizing functional complaints in patients seeking outpatient low-vision services in the United States.

Ophthalmology, 121(8), 1655-1662.

https://doi.org/10.1016/j.ophtha.2014.02.030

Burggraaff, M. C., van Nispen, R. M. A., Hoek, S., Knol, D. L., \& van Rens, G. H. M. B. (2010). Feasibility of the Radner Reading Charts in low-vision patients. Graefe's Archive for Clinical and Experimental Ophthalmology, 248(11), 1631-1637. https://doi.org/10.1007/soo417-010-1402-1

Burmistrov, I., Zlokazova, T., Ishmuratova, I., \& Semenova, M. (2016). Legibility of light and ultra-light fonts: Eye tracking study. In Proceedings of the gth Nordic Conference on HumanComputer Interaction (pp. 1-6). https://doi.org/10.1145/2971485.2996745

Calossi, A., Boccardo, L., Fossetti, A., \& Radner, W. (2014). Design of short Italian sentences to assess near vision performance. Journal of Optometry, 7(4), 203-209. https://doi.org/10.1016/j.optom.2014.05.001

Carter, H. (1937). Optical scale in typefounding. Typography, 4, 2-6.

Chung, S. T. L. (2014). Size or spacing: Which limits letter recognition in people with age-related macular degeneration? Vision Research, 101, 167-176. https://doi.org/10.1016/j.visres.2014.06.015
Chung, S. T. L., \& Bernard, J.-B. (2018). Bolder print does not increase reading speed in people with central vision loss. Vision Research, 153, 98-104. https://doi.org/10.1016/j.visres.2018.10.012

Chung, S. T. L., Mansfield, J. S., \& Legge, G. E. (1998). Psychophysics of reading. XVIII. The effect of print size on reading speed in normal peripheral vision. Vision Research, 38(19), 2949-2962. https://doi.org/10.1016/Soo42-6989(98)00072-8

Dobres, J., Reimer, B., Parikhal, L., Wean, E., \& Chahine, N. (2015). The Incredible Shrinking Letter: How Font Size Affects the Legibility of Text Viewed in Brief Glances. In Proceedings of the 8th International Driving Symposium on Human Factors in Driver Assessment, Training, and Vehicle Design: driving assessment 2015 (pp. 435-442).

https://doi.org/10.17077/drivingassessment.1605

Dyson, M. C., \& Beier, S. (2016). Investigating typographic differentiation: Italics are more subtle than bold for emphasis. Information Design Journal, 22(1), 3-18. https://doi.org/10.1075/idj.22.1.02dys

Fletcher, D. C., Schuchard, R. A., \& Watson, G. (1999). Relative locations of macular scotomas near the PRL: effect on low vision reading. Journal of Rehabilitation Research and Development, 36(4), 356-364.

Galvin, K. (2014). Online and print inclusive design and legibility considerations. https://www.visionaustralia.org/services/ digital-access/blog/12-03-2014/online-and-print-inclusivedesign-and-legibility-considerations

Garvey, P. M., Zineddin, A. Z., \& Pietrucha, M. T. (2001). Letter legibility for signs and other large format applications. In Proceedings of the Human Factors and Ergonomics Society Annual Meeting, 45(18), 1443-1447. https://doi.org/10.1177/154193120104501828

Garvey, P. M., Eie, W.-Y., \& Klenna, M. J. (2016). The effect of font characteristics on large format display. Interdisciplinary Journal of Signage and Wayfinding, 1(1). https://doi.org/10.15763/issn.2470-9670.2016.v1.i1.a3

Hess, R. F., Dakin, S. C., \& Kapoor, N. (2000). The foveal 'crowding' effect: Physics or physiology? Vision Research, 40(4), 365-370. https://doi.org/10.1016/Soo42-6989(99)oo193-5

Kingery, D., \& Furuta, R. (1997). Skimming electronic newspaper headlines: A study of typeface, point size, screen resolution, and monitor size. Information Processing \& Management, 33(5), 685-696. https://doi.org/10.1016/So306-4573(97)0o025-3 
Kitchel, J. (2013). APH guidelines for print document design. https://www.aph.org/aph-guidelines-for-print-documentdesign

Larson, K., \& Carter, M. (2016). Sitka: A collaboration between type design and science. In M. C. Dyson \& C. Y. Suen (Eds.), Digital Fonts and Reading (Vol. 1, pp. 37-53). World Scientific. https://doi.org/10.1142/9789814759540_0003

Legge, G. E., Rubin, G. S., Pelli, D. G., \& Schleske, M. M. (1985). Psychophysics of reading - II. Low vision. Vision Research, 25(2), 253-265. https://doi.org/10.1016/0042-6989(85)90118-X

Liu, L., \& Arditi, A. (2001). How crowding affects letter confusion. Optometry \& Vision Science, 78(1), 50-55. https://doi.org/10.1097/00006324-200101010-00014

Maaijwee, K., Mulder, P., Radner, W., \& Van Meurs, J. C. (2008). Reliability testing of the Dutch version of the Radner Reading Charts. Optometry and Vision Science, 85(5), 353-358. https://doi.org/10.1097/OPX.obo13e31816bf58b

Mansfield, J. S., Legge, G. E., \& Bane, M. C. (1996). Psychophysics of reading. XV: Font effects in normal and low vision. Investigative Ophthalmology \& Visual Science, 37(8), 1492-1501.

Morris, R. A., Aquilante, K., Yager, D., \& Bigelow, C. (2002). P-13: Serifs slow RSVP reading at very small sizes, but don't matter at larger sizes. In SID Symposium Digest of Technical Papers, 33(1), 244-247. Oxford, UK: Blackwell Publishing Ltd. https://doi.org/10.1889/1.1830242

Munch, I. C., Jørgensen, A. R., \& Radner, W. (2016). The Danish version of the Radner Reading Chart: Design and empirical testing of sentence optotypes in subjects of varying educational background. Acta Ophthalmologica, 94(2), 182-186. https://doi.org/10.1111/aos.12845

Neelam, K., Nolan, J., Chakravarthy, U., \& Beatty, S. (2009). Psychophysical Function in Age-related Maculopathy. Survey of Ophthalmology, 54(2), 167-210. https://doi.org/10.1016/j.survophthal.2008.12.003

Pušnik, N., Podlesek, A., \& Možina, K. (2016). Typeface comparison - Does the $\mathrm{x}$-height of lower-case letters increased to the size of upper-case letters speed up recognition? International Journal of Industrial Ergonomics, 54, 164-169. https://doi.org/10.1016/j.ergon.2016.06.002

Radner, W. (2017). Reading charts in ophthalmology. Graefe's Archive for Clinical and Experimental Ophthalmology, 255(8), 1465-1482. https://doi.org/10.1007/soo417-017-3659-0
Radner, W., \& Diendorfer, G. (2014). English sentence optotypes for measuring reading acuity and speed - The English version of the RADNER Reading Charts. Graefe's Archive for Clinical and Experimental Ophthalmology, 252(8), 1297-1303. https://doi.org/10.1007/so0417-014-2646-y

Radner, Wolfgang, Obermayer, W., Richter-Mueksch, S., Willinger, U., Velikay-Parel, M., \& Eisenwort, B. (2002). The validity and reliability of short German sentences for measuring reading speed. Graefe's Archive for Clinical and Experimental Ophthalmology, 240(6), 461-467. https://doi.org/10.1007/s00417-002-0443-5

Rasmussen, A., Bloch, S. B., Fuchs, J., Hansen, L. H., Larsen, M., LaCour, M., Lund-Andersen, H., \& Sander, B. (2013). A 4-year longitudinal study of 555 patients treated with ranibizumab for neovascular age-related macular degeneration.

Ophthalmology, 120(12), 2630-2636.

https://doi.org/10.1016/j.ophtha.2013.05.018

Rasmussen, A., Brandi, S., Fuchs, J., Hansen, L. H., Lund-Andersen, H., Sander, B., \& Larsen, M. (2015). Visual outcomes in relation to time to treatment in neovascular age-related macular degeneration. Acta Ophthalmologica, 93(7), 616-620. https://doi.org/10.1111/aos.12781

Rosa, A. M., Farinha, C. L., Radner, W., Diendorfer, G., Loureiro, M. F., \& Murta, J. N. (2016). Development of the Portuguese version of a standardized reading test: The RadnerCoimbra Charts. Arquivos Brasileiros de Oftalmologia, 79(4), 238-242. https://doi.org/10.5935/0004-2749.20160068

Sheedy, J. E., Subbaram, M. V., Zimmerman, A. B., \& Hayes, J. R. (2005). Text legibility and the letter superiority effect. Human Factors: The Journal of the Human Factors and Ergonomics Society, 47(4), 797-815. https://doi.org/10.1518/001872005775570998

Smuc, M., Windhager, F., Siebenhandl, K., \& Egger, S. (2007). Impaired Visibility Typeface Test- Report. Report In-Safety A, 2.

Soleimani, H., \& Mohammadi, E. (2012). The effect of text typographical features on legibility, comprehension, and retrieval of EFL learners. English Language Teaching, 5(8), 207. https://doi.org/10.5539/elt.v5n8p207

Szpiro, S. F. A., Hashash, S., Zhao, Y., \& Azenkot, S. (2016). How people with low vision access computing devices: Understanding challenges and opportunities. In Proceedings of the 18th International ACM SIGACCESS Conference on Computers and Accessibility (pp. 171-180). https://doi.org/10.1145/2982142.2982168 
Tarita-Nistor, L., Lam, D., Brent, M. H., Steinbach, M. J., \& González, E. G. (2013). Courier: A better font for reading with age-related macular degeneration. Canadian Journal of Ophthalmology/Journal Canadien d'Ophtalmologie, 48(1), 56-62. https://doi.org/10.1016/j.jcjo.2012.09.017

Tracy, W. (1986). Letters of credit: A view of type design. London: Gordon Fraser.

Tunold, S., Radianti, J., Gjøsæter, T., \& Chen, W. (2019). Perceivability of Map Information for Disaster Situations for People with Low Vision. Lecture Notes in Computer Science, 342-352. https://doi.org/10.1007/978-3-030-23560-4_25

Unger, G. (2018). Theory of type design. naio10.

Virsu, V., \& Rovamo, J. (1979). Visual resolution, contrast sensitivity, and the cortical magnification factor. Experimental Brain Research, 37(3), 475-494. https://doi.org/10.1007/BFoo236818

Wallace, J. M., Chung, S. T. L., \& Tjan, B. S. (2017). Object crowding in age-related macular degeneration. Journal of Vision, 17(1), 33. https://doi.org/10.1167/17.1.33

Waller, R. (2007). Comparing typefaces for airport signs. Information Design Journal, 15(1), 1-15. https://doi.org/10.1075/idj.15.1.01wal

Wong, W. L., Su, X., Li, X., Cheung, C. M. G., Klein, R., Cheng, C.-Y., \& Wong, T. Y. (2014). Global prevalence of age-related macular degeneration and disease burden projection for 2020 and 2040: A systematic review and meta-analysis.

The Lancet Global Health, 2(2), e106-e116. https://doi.org/10.1016/S2214-109X(13)70145-1

Xiong, Y.-Z., Lorsung, E. A., Mansfield, J. S., Bigelow, C., \& Legge, G. E. (2018). Fonts Designed for Macular Degeneration: Impact on Reading. Investigative Ophthalmology \& Visual Science, 59(10), 4182-4189.

https://doi.org/10.1167/iovs.18-24334

Yager, D., Aquilante, K., \& Plass, R. (1998). High and low luminance letters, acuity reserve, and font effects on reading speed. Vision Research, 38(17), 2527-2531. https://doi.org/10.1016/Soo42-6989(98)00116-3

\section{About the authors}

Designer and Professor WSR Sofie Beier is head of Centre for Visibility Design at the Royal Danish Academy. She is the author of the books Type Tricks: Your personal guide to type design and Reading Letters: designing for legibility and has published numerous academic papers on typeface legibility.

Email: sbe@kglakademi.dk

Chiron Oderkerk is a postdoctoral researcher at the Royal Danish Academy at Centre for Visibility Design. Having done a PhD in Psychology at the University of Copenhagen, his scientific research focuses on mathematical modeling of visual attentional processes.

Email: chiron.oderkerk@gmail.com

Birte Bay is Master of Optometry from the University of Aarhus and clinical study study coordinator at the the Departments of Ophthalmology at the Rigshospitalet and in Roskilde.

Email: birtebay@gmail.com

Michael Larsen is Professor of Clinical Ophthalmology at the Rigshospitalet and the University of Copenhagen. His research field is retinal diseases and non-invasive studies of ocular physiology.

Email:miclaro1@regionh.dk
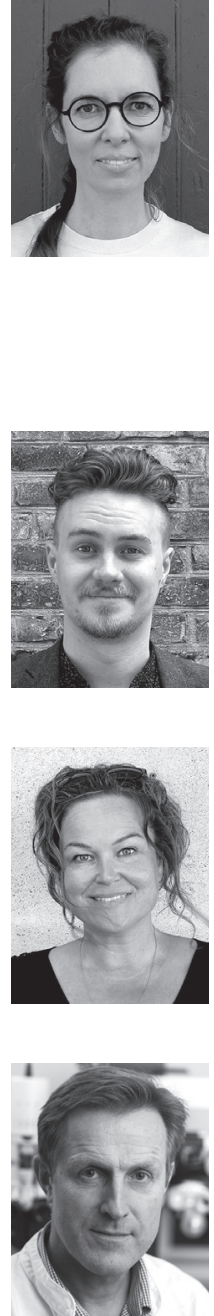